\title{
The impact of COVID-19 on rheumatology patients in a large UK centre using an innovative data collection technique: prevalence and effect of social shielding
}

\author{
N. Cleaton ${ }^{1}$ (D) - S. Raizada ${ }^{1} \cdot$ N. Barkham ${ }^{1} \cdot$ S. Venkatachalam ${ }^{1} \cdot$ T. P. Sheeran ${ }^{1} \cdot$ T. Adizie ${ }^{1} \cdot$ H. Sapkota ${ }^{1} \cdot$ B. M. Singh $^{2}$. \\ J. Bateman ${ }^{1}$ (iD
}

Received: 3 July 2020 / Accepted: 5 August 2020 / Published online: 9 February 2021

(c) The Author(s), under exclusive licence to Springer-Verlag GmbH, DE part of Springer Nature 2021

\begin{abstract}
Objectives We sought to gain insight into the prevalence of COVID-19 and the impact stringent social distancing (shielding) has had on a large cohort of rheumatology (RD) follow-up patients from a single large UK centre.

Methods We linked COVID-19-related deaths, screening and infection rates to our RD population (1.2.20-1.5.20) and audited active rheumatology follow-up patients through survey data communicated via a linked mobile phone SMS message. We assessed epidemiology, effect of stringent social distancing (shielding) and quality of life (HRQoL) by Short Form 12 (SF12).

Results There were 10,387 active follow-up patients, 7911 had linked mobile numbers. 12/10,387 RD patients died from COVID-19 (0.12\%); local population 4131/7,415,149 (0.12\%). For patients with mobile phones, 1693/7911 (21\%) responded and of these, 1605 completed the SF12. Inflammatory arthritis predominated 1174/1693 (69\%); 792/1693 (47\%) were shielding. Advice on shielding/distancing was followed by 1372/1693(81\%). 61/1693 (4\%) reported COVID-19 (24/61 shielding); medication distribution was similar in COVID and non-COVID patients. Mental SF12 (MCS) but not physical (PCS) component scores were lower in COVID (60) vs. non-COVID (1545), mean differences: MCS, - 3.3; 95\% CI - 5.2 to $-1.4, P<0.001$; PCS, $-0.4 ; 95 \% \mathrm{CI},-2.1$ to 1.3$)$. In 1545 COVID-negative patients, those shielding had lower MCS $(-2.1 ; 95 \% \mathrm{CI}-2.8$ to -1.4$)$ and PCS $(-3.1,95 \% \mathrm{CI}-3.7$ to -2.5$)$, both $P<0.001$.

Conclusions Our full RD cohort had no excess of COVID deaths compared to the general local population. Our survey data suggest that shielding adversely affects both mental and physical health in RD. These data broaden our understanding of shielding, indicating need for further study.
\end{abstract}

Keywords Rheumatic disease $\cdot$ Quality of life indicators $\cdot$ Health care delivery $\cdot$ COVID-19 $\cdot$ Health service research . Quality improvement

J. Bateman

jamesbateman@nhs.net

N. Cleaton

Natasha.cleaton@nhs.net

S. Raizada

sabrina.raizada@nhs.net

N. Barkham

nick.barkham@nhs.net

S. Venkatachalam

s.venkatachalam@nhs.net

T. P. Sheeran

t.sheeran@nhs.net
T. Adizie

tochukwu.adizie1@nhs.net

H. Sapkota

hem.sapkota@nhs.net

B. M. Singh

baldev.singh@nhs.net

1 Departments of Rheumatology, Royal Wolverhampton NHS Trust, Wolverhampton, UK

2 Diabetes and Endocrinology, Royal Wolverhampton NHS Trust, Wolverhampton, UK 


\section{Introduction}

Little is understood about the impact of the COVID-19 pandemic on health and quality of life in patients with rheumatic disease (RD). National public health guidance for high-risk rheumatology patient groups in the United Kingdom (UK) have been developed through a combination of recommendations from the European League Against Rheumatism (EULAR), [1] and the British Society for Rheumatology (BSR). BSR produced a risk-predictor model to identify patients remaining on current immunomodulatory medications who should follow stringent social isolation measures, termed 'shielding' [2]. 'Shielding' rules require that patients remain isolated in their homes, having minimal contact with others, for minimum of 12 weeks [3, 4]. This guidance is under frequent review, with potential extensions.

Various methods have been used by rheumatology departments nationwide to distribute these important public health messages. We have recently reported an innovative technique using targeted SMS video messages to allow patients to self-score during the COVID-19 pandemic and self-stratify their own risk to facilitate this process [5].

Understanding the impacts of COVID-19 in RD patients is important for future planning in both the immediate and longer term. Lessons learned from the pandemic are crucial in shaping future response policies and should be shared internationally.

While case series [6], international clinical trials and registry studies are ongoing the wider impacts of COVID-19 on RD patients is poorly understood [7, 8]. In the UK, data are collected by different organisations within the NHS [9], ONS 2020 [10], and large GP registry studies [11]. These datasets and repositories of amalgamated data give limited insight into other aspects of the pandemic impact, in particular shielding, on physical and mental health. Primary care datasets lack details of treatments given in secondary care. Large datasets may be prone to error [12].

We sought to gain insight into the prevalence of COVID19 and the impact stringent social isolation (shielding) has had on a large cohort of rheumatology (RD) follow-up patients. Here, we report the preliminary results assessing the effects of the COVID-19 pandemic on mortality, infection rate, shielding rates and compliance and Health-Related Quality of Life (HRQoL) at a large UK centre.

\section{Methods}

We audited all patients under active follow-up at our centre (Royal Wolverhampton NHS Trust) by linking data from three data sources: our hospital electronic patient record (EPR); regional COVID-19 laboratory test results (1.2.20-1.5.20); and the primary and secondary care allcause mortality report for our area (1.2.20-1.5.20) to assess infection rate and mortality.

We designed and piloted a 10-min 70-item questionnaire with two Patient Participation Groups, a national charity (Hibbs Lupus Trust), clinicians, and rheumatology nurse specialists as part of our ongoing service evaluation and development and evaluation in the pandemic.

We contacted patients using a recently described mobile phone SMS messaging methodology [5]. Patients with a validated mobile telephone number linked to their EPR on 24.4.2020 were sent an SMS message with an embedded link to a web-based survey, generated through SurveyMonkey 2020. The SMS messages were distributed via our SMS provider (Healthcare Communications UK). The message invited patients to participate and on following the link, patients were provided with explanatory information about the service evaluation prior to participating.

The questionnaire (supplement 1) asked patients to voluntarily self-report a range of metrics including demographics, diagnosis, and medication [16-questions]; exposure to COVID, COVID status and symptoms [30]; shielding status and shielding adherence [5]; and current health [7]. Patients were asked to volunteer their mobile number to enable us to link responses to patients EPR for audit purposes. On completion, patients were offered a validated HRQoL survey using Short Form 12 (SF12) questionnaires [12], which assess physical (PCS) and mental component scores (MCS) on a $0-100$ scale (0-lowest score) [13].

We verified self-reported positive COVID infection status against our EPR and a regional COVID-19 laboratory dataset. Data were analysed using SPSS version-26. This work was given rapid approval as a service evaluation by the Royal Wolverhampton NHS Trust Management Committee, as per national NHS England ethics requirements, is exempt from formal research ethics committee review. Participation was voluntary, and formal consent was not required. This work is compliant with European Union General Data Protection Regulation; no additional consent for sending healthcare SMS messages is required. [14].

\section{Results}

\section{Mortality audit data}

On 18.4.20, there were 10,387 patients in our cohort (mean age 62.3 years (95\% CI 62.0, 62.6)). We identified 78/10,387 (1\%) who had COVID-19 swab tests by the 1.5.2020. As shown in Table 1, 35/78 (45\%) had positive results and there were $12(34 \%)$ deaths (1 diagnosed post-mortem). Nine of the $12(75 \%)$ deaths had inflammatory arthritis comparable 
Table 1 A: Audit of 78/10,387 follow-up patients that had COVID swabs taken by 1.5.2020; B: mortality data of the 78 patients swabbedgender and ethnicity reported as $n$ (\% of total group; $\%$ of deaths in group)

\begin{tabular}{lccc}
\hline & $\begin{array}{l}\text { All swabbed } \\
n=78\end{array}$ & $\begin{array}{l}\text { Positive swab } \\
n=35\end{array}$ & $\begin{array}{l}\text { Negative swab } \\
n=43\end{array}$ \\
\hline $\begin{array}{l}\text { A-Audit data } \\
\text { Age, years (95\% CI) }\end{array}$ & $66.6(63.4,69.8)$ & $68.0(64.3,71.7)$ & $65.6(60.7,70.5)$ \\
$\begin{array}{l}\text { Gender and ethnicity } \\
\text { Female }\end{array}$ & $48(61.5 \%)$ & $19(54.3 \%)$ & $29(67.4 \%)$ \\
Male & $30(38.5 \%)$ & $16(45.7 \%)$ & $14(32.6 \%)$ \\
BAME & $42(53.8 \%)$ & $7(20.0 \%)$ & $8(18.6 \%)$ \\
B-Mortality data & $14(17.9 \%)$ & $12(34.3 \%)$ & $2(4.7 \%)$ \\
Deaths & $69.8(64.3,75.3)$ & $70.8(64.4,77.2)$ & $63.5(57.3,69.7)$ \\
Age, years (95\% CI) & & & $1(2.3 \% ; 50.0 \%)$ \\
Gender and ethnicity & $8(10.3 \% ; 57.1 \%)$ & $7(20.0 \% ; 58.3 \%)$ & $1(2.3 \% ; 50.0 \%)$ \\
Female & $6(7.7 \% ; 42.9 \%)$ & $5(14.3 \% ; 41.7 \%)$ & 0 \\
Male & $4(5.1 \% ; 28.6 \%)$ & $4(11.4 \% ; 33.3 \%)$ & \\
BAME & & & \\
\hline
\end{tabular}

$B A M E$ Black Asian Minority Ethnic group to a recent study reporting $74 \%$ of patients to have inflammatory arthritis in this cohort: [15] mean age 70.8 years $(95 \%$ CI 64.4, 77.2); 7 female, 8 Caucasian. Of 43 patients with a negative swab, 2 died (Table 1). Overall, $0.12 \%$ of our RD cohort died from COVID-19.

\section{Survey data}

Of the total 10,387 patients, SMS evaluations were sent to 7911 patients with validated mobile numbers linked to their EPR. Severn days following survey distribution, 1966 (25\%) responses had been received; $1693 / 7910$ (21\%) were returned with completed clinical data and 1605/1693 (95\%) had completed both clinical data and all SF12 questions. Surveys typically took $10 \mathrm{~min}$ and $19 \mathrm{~s}$ to complete. Respondents were mean 59.4 years (95\% CI 58.8, 60.0), 1175 (69\%) female and 1589 (94\%) Caucasian. The primary diagnosis was inflammatory arthritis: rheumatoid arthritis (RA) 846 (50\%), psoriatic arthritis 267 (16\%), and ankylosing spondylitis $82(5 \%)$ (Table 2).

Of the 1693 respondents, 61 (3.6\%) of surveyed patients reported being diagnosed with COVID-19: 8 confirmatory swab results; 3 clinical diagnoses with 'false-negative' swabs; 50 with a clinical diagnosis, not swabbed in line with UK policy at that time [16]. These COVID infection cases were verified against data from patients EPR and local pathology results. Severn of the 61 (11.5\%) patients were hospitalised, 2 requiring intensive care. Symptoms were frequently reported to last more than 2 weeks $(47.5 \%)$ and symptom profiles were as expected [17]. The primary diagnosis in these COVID-19 patients was RA (21 [36.1\%]), 27 (44.3\%) were taking conventional-Disease Modifying Antirheumatic Drugs (c-DMARDs), 14 (23.0\%) biologicDMARDs (b-DMARDs), and 15 (24.6\%) were taking glucocorticoids as part of their RD management. Nineteen (31.1\%) were not taking any specific rheumatological therapies, none of the surveyed patients reported having had cyclophosphamide within the past 6 months (Table 3).

\section{HRQoL data}

HRQoL data (SF12) were collected for 1605/1693 survey respondents. There were significantly lower MCS in the COVID-19-infected group $(n=60)$ compared with noninfected ( $n=1545)$ (mean: 38.9 (95\% CI 36.9, 40.9) vs. mean: 42.2 (95\% CI 41.8, 42.6); mean difference: - 3.3; $95 \% \mathrm{CI}-5.2,-1.4, P<0.001)$, but no difference in PCS $(-0.4 ;-2.1,1.3)$ (Table 2).

When examining HRQoL in the cohort of patients without COVID-19 (1545), the 'shielding' group had significantly lower mental $(-2.1 ;-2.9,-1.4, P<0.001)$ and physical health $(-2.2 ;-3.8,-2.5 ; P<0.001)$ than those not shielding. Patients adhered well to shielding (Table 2).

There were no differences in MCS between patients on c-DMARDs and b-DMARDs $(0.6 ; 0.1,2.4)$. There were small differences in MCS between non-inflammatory and ARD patients $(1.2 ; 0.1,2.4, P=0.035)$, and BAME and Caucasian patients $(1.5 ; 0.1,3.0, P=0.044)$. There were no differences in PCS between medication, diagnosis, or ethnic groups (NI vs. ARD: $0.3 ;-0.7,1.2, P=0.602$. b-DMARD vs. c-DMARD: $-0.1 ;-1.0,0.9$. BAME vs. Caucasian: $-0.8 ;-2.3,0.8$ ) (Table 2).

\section{Shielding adherence data}

As shown in Table 4, 662/792 (84\%) in the shielding group and $710 / 901(79 \%)$ in the non-shielding group report following shielding or distancing advice. Of the 
Table 2 A: Summary of survey respondent results comparing demographics, diagnosis $(n=1693)$ overall and between patients that have been diagnosed and those patients that have not been diagnosed with COVID-19 infection. B: HRQoL (SF12) scores are shown for respondents who completed SF12 scores $(n=1605)$ overall and between patients that have been diagnosed and those patients that have not been diagnosed with COVID-19 infection

\begin{tabular}{|c|c|c|c|}
\hline $\begin{array}{l}\text { A-Respondents completing ques- } \\
\text { tionnaire }\end{array}$ & All responders & Diagnosed with COVID & Not diagnosed COVID-19 \\
\hline All complete responders & $1693 / 7910(21.4 \%)$ & $\begin{array}{l}61 \text { ( } 8 \text { swab positive, } 3 \text { false negative, } \\
50 \text { clinical) }\end{array}$ & 1632 \\
\hline Age (mean, $95 \% \mathrm{CI}$ ) & 59.4 years $(58.8,60.0)$ & 59.3 years $(56.2,62.4)$ & 59.4 years $(58.8,60.0)$ \\
\hline \multicolumn{4}{|l|}{ Gender } \\
\hline Female & $1175(69.4 \%)$ & $48 ; 4.1 \%(78.7 \%)$ & $1127 ; 95.9 \%(69.1 \%)$ \\
\hline Male & $518(30.6 \%)$ & $13 ; 2.5 \%(21.3 \%)$ & $505 ; 97.5 \%(30.9 \%)$ \\
\hline BAME & $104(6.1 \%)$ & $8 ; 7.7 \%(13.1 \%)$ & $96 ; 92.3 \%(5.9 \%)$ \\
\hline Shielding group & $792(46.8 \%)$ & $24 ; 3.0 \%(39.3 \%)$ & $768 ; 97.0 \%(47.1 \%)$ \\
\hline Reported COVID-19 exposure & $246(14.5 \%)$ & $48 ; 19.5 \%(78.7 \%)$ & $198 ; 80.5 \%(12.1 \%)$ \\
\hline \multicolumn{4}{|l|}{ Diagnosis } \\
\hline Rheumatoid arthritis & $846(50.0 \%)$ & $22 ; 2.6 \%(36.1 \%)$ & $824 ; 97.4 \%(50.5 \%)$ \\
\hline Osteoarthritis & $103(6.1 \%)$ & $4 ; 3.9 \%(6.6 \%)$ & $99 ; 96.1 \%(6.1 \%)$ \\
\hline Ankylosing spondylitis/SPA & $82(4.8 \%)$ & $3 ; 3.7 \%(4.9 \%)$ & $79 ; 96.3 \%(4.8 \%)$ \\
\hline Psoriatic arthritis & $267(15.8 \%)$ & $9 ; 3.4 \%(14.8 \%)$ & $258 ; 96.6 \%(15.8 \%)$ \\
\hline Systemic lupus erythematosus & $42(2.5 \%)$ & $3 ; 7.1 \%(4.9 \%)$ & $39 ; 92.9 \%(2.3 \%)$ \\
\hline Vasculitis any & $14(0.8 \%)$ & $1 ; 7.1 \%(1.6 \%)$ & $13 ; 92.9 \%(0.3 \%)$ \\
\hline Myositis/dermatomyositis & $11(0.7 \%)$ & $0(0 \%)$ & $11 ; 100 \%(0.7 \%)$ \\
\hline Scleroderma/systemic sclerosis & $24(1.4 \%)$ & $0(0 \%)$ & $24 ; 100 \%(1.5 \%)$ \\
\hline Osteoporosis & $82(4.8 \%)$ & $5 ; 6.1 \%(8.2 \%)$ & $77 ; 93.9 \%(4.7 \%)$ \\
\hline Other & $222(13.1 \%)$ & $14 ; 6.3 \%(23.0 \%)$ & $208 ; 93.7 \%(12.8 \%)$ \\
\hline -HRQoL respondents & $\begin{array}{l}11 \text { respondents } \\
=1605\end{array}$ & $\begin{array}{l}\text { Diagnosed with COVID } \\
n=60\end{array}$ & $\begin{array}{l}\text { gnosed COVID-19 } \\
5\end{array}$ \\
\hline
\end{tabular}

MCS

SF12 MCS (95\% CI)

Shielding vs. non-shielding

NI diagnosis vs. ARD diagnosis Any biologic vs. any DMARD

BAME vs. Caucasian

PCS

SF12 PCS (95\% CI)

Shielding vs. non-shielding

NI diagnosis vs. ARD diagnosis Any biologic vs. any DMARD BAME vs. Caucasian

\section{$42.0(41.6,42.4)$}

$+40.9(40.5,41.3) ; 43.0(42.7$, 43.3)

$38.9(36.9,40.9)$

$42.2(41.8,42.6)$

$37.2(35.4,39.0) ; 39.9(37.8,42.0) \quad \mathbf{+ 4 1 . 0}(\mathbf{4 0 . 6}, \mathbf{4 1 . 4}) ; \mathbf{4 3 . 2}(\mathbf{4 2 . 9}$, 43.5)

*41.1 (40.7, 41.5); 42.3 (42, 42.6) *33.6 (31.0, 36.2); 39.9 (38.0, 41.8) $41.5(41.1,41.9) ; 42.3(42.0,42.6)$ 41.9 (41.6, 42.2); 42.5 (42.1, 42.9) 38.2 (35.9, 40.5); 40.9 (39.1, 42.7) $42.0(41.7,42.3) ; 42.6(42.2,43.0)$

*40.6 (40.2, 41.0); 42.1 ((41.7, 38.3 (36.0, 40.5); 39.0 (37.0, 41.0) 40.8 (40.4, 41.2); $42.2(41.8,42.6)$ 42.5)

$\begin{array}{ccc}38.4(38.1,38.7) & 38.0(36.4,39.6) & 38.4(38.1,38.7) \\ +\mathbf{3 6 . 7}(\mathbf{3 6 . 4 , 3 7 . 0 )} ; \mathbf{3 9 . 8}(\mathbf{3 9 . 5}, & 36.6(35.2,38.0) \text { vs. } 38.8(37.0, & \begin{array}{c}\mathbf{+ 3 6 . 7}(\mathbf{3 6 . 4 , 3 7 . 0}) \text { vs. 39.8 (39.5, } \\ \mathbf{4 0 . 1})\end{array} \\ \mathbf{4 0 . 1}) & 40.6) & \end{array}$

38.1 (37.8, 38.4); $38.4(38.1,38.7) \quad 37.2(35.4,39.1) ; 38.4(36.8,40.0) 38.2(37.9,38.5) ; 38.4(38.1,38.7)$ 41.9 (41.6, 42.2); 42.5 (42.1, 42.9) $38.2(35.9,40.5) ; 40.9(39.1,42.7) 42.0(41.7,42.3) ; 42.6(42.2,43.0)$ $39.1(38.7,39.5) ; 38.3(38.0,38.6) \quad 37.9(36.3,39.5) ; 38.0(36.3,39.7) 39.2(38.8,39.6) ; 38.3(38.0,38.6)$

Significant results highlighted in bold

SPA spondyloarthropathy, BAME black and minority ethnic, SF12 Short form 12, MCS mental component score, PCS physical component Score, $N I$ non-inflammatory, $A R D$ autoimmune rheumatic disease

${ }^{+} P<0.001$

$* P<0.05$

1693 respondents, $940(56 \%)$ of the patients' reported having received and watched the advice sent by the rheumatology department to patients in the form of a video link via SMS messaging. While a significantly higher proportion of the shielding group than the non-shielding group $(414 / 792[52 \%]$ vs. $135 / 901[15 \%], P=0.05)$ 
Table 3 A comparison of the proportions of patients on specific rheumatological treatments and rates of infection in patients within different treatment groups $(n=1693)$

\begin{tabular}{|c|c|c|c|}
\hline Respondents completing questionnaire & All responders 1693 & $\begin{array}{l}\text { COVID-19 infection } \\
61 \text { ( } 8 \text { swab positive, } 3 \text { false } \\
\text { negative, } 50 \text { clinical })\end{array}$ & No COVID-19 infection 1632 \\
\hline \multicolumn{4}{|l|}{ Therapy by treatment category } \\
\hline DMARD any* & $1017(60.1 \%)$ & $27 ; 2.7 \%(44.3 \%)$ & $90 ; 97.3 \%(60.7 \%)$ \\
\hline Biologic any* & $543(32.1 \%)$ & $14 ; 2.7 \%(23.0 \%)$ & $529 ; 97.4 \%(32.4 \%)$ \\
\hline Glucocorticoid any* & $316(18.7 \%)$ & $15 ; 4.7 \%(24.6 \%)$ & $301 ; 95.3 \%(18.4 \%)$ \\
\hline Cyclophosphamide any ${ }^{\alpha}$ & $16(0.9 \%)$ & $0(0 \%)$ & $16 ; 100 \%(0.9 \%)$ \\
\hline No rheumatological therapy & $351(20.7 \%)$ & $19 ; 5.4 \%(31.1 \%)$ & $332 ; 94.6 \%(20.3 \%)$ \\
\hline \multicolumn{4}{|l|}{ Monotherapy $^{\dagger}$} \\
\hline $\begin{array}{l}\text { DMARD monotherapy (excluding HCQ and } \\
\text { Sulfasalazine) })^{\dagger}\end{array}$ & $283(16.7 \%)$ & $6 ; 2.1 \%(9.8 \%)$ & $277 ; 97.9 \%(17.0 \%)$ \\
\hline HCQ monotherapy ${ }^{\dagger}$ & $84(5.0 \%)$ & $4 ; 4.8 \%(6.6 \%)$ & $80 ; 95.2 \%(49.0 \%)$ \\
\hline Biologic monotherapy $^{\dagger}$ & $191(11.3 \%)$ & $9 ; 4.7 \%(14.8 \%)$ & $182 ; 95.3 \%(11.2 \%)$ \\
\hline Glucocorticoid monotherapy $^{\dagger}$ & $103(5.2 \%)$ & $6 ; 5.8 \%(9.8 \%)$ & $97 ; 94.2 \%(5.9 \%)$ \\
\hline Cyclophosphamide monotherapy & $1(0.1 \%)$ & $0(0 \%)$ & $1 ; 100 \%(0.1 \%)$ \\
\hline \multicolumn{4}{|l|}{ Specific biologic monotherapy groups } \\
\hline TNF inhibitors & $105(6.2 \%)$ & $5 ; 4.8 \%(8.2 \%)$ & $100 ; 95.2 \%(6.1 \%)$ \\
\hline IL6/6R inhibitors & $15(0.9 \%)$ & $1 ; 6.7 \%(1.6 \%)$ & $14 ; 93.3 \%(0.9 \%)$ \\
\hline IL17 inhibitors & $25(1.5 \%)$ & $1 ; 4 \%(1.6 \%)$ & $24 ; 96 \%(1.5 \%)$ \\
\hline CD80/86 blocker & $7(0.4 \%)$ & $1 ; 14.3 \%(1.6 \%)$ & $6 ; 85.7 \%(0.4 \%)$ \\
\hline IL12/IL23-inhibitor & $5(0.3 \%)$ & $0(0 \%)$ & $5 ; 100 \%(0.3 \%)$ \\
\hline Anti-CD20 & $19(1.1 \%)$ & $1 ; 5.3 \%(1.6 \%)$ & $18 ; 94.7 \%(1.1 \%)$ \\
\hline JAK-i & $15(0.9 \%)$ & $0(0 \%)$ & $15 ; 100 \%(0.9 \%)$ \\
\hline \multicolumn{4}{|c|}{ Glucocorticoid monotherapy groups (no other additional DMARD) } \\
\hline$<5 \mathrm{mg}$ & $24(1.4 \%)$ & $2 ; 8.3 \%(3.3 \%)$ & $22 ; 91.7 \%(1.3 \%)$ \\
\hline $5-9 \mathrm{mg}$ & $32(1.9 \%)$ & $1 ; 3.1 \%(1.6 \%)$ & $31 ; 96.9 \%(1.9 \%)$ \\
\hline $10-14 \mathrm{mg}$ & $7(0.5 \%)$ & $0(0 \%)$ & $7(0.4 \%)$ \\
\hline $15-19 \mathrm{mg}$ & $4(0.2 \%)$ & $0(0 \%)$ & $4(0.2 \%)$ \\
\hline$\geq 20 \mathrm{mg}$ & $3(0.2 \%)$ & $0(0 \%)$ & $3(0.2 \%)$ \\
\hline Regular IM/IV & $33(1.9 \%)$ & $3 ; 9.1 \%(4.9 \%)$ & $30 ; 90.9 \%(1.8 \%)$ \\
\hline
\end{tabular}

No rheumatological therapy refers to patients not receiving specific treatment $(n=351)$

$H C Q$ Hydroxychloroquine, JAK-i Janus Kinase Inhibitor

*DMARD/Biologic/Glucocorticoid ANY groups include all patients taking these medications including patients on combination therapy

${ }^{\dagger}$ Monotherapy—-patients on a single agent, excluding all other medications listed in subheadings

${ }^{\alpha}$ Cyclophosphamide — all patients having received cyclophosphamide within the last 6 months

reported they had been stringently shielding over the past week (consistent with social shielding advice). Significantly fewer of the shielding group reported minimal contact, i.e. rarely leaving the house consistent with distancing advice (365/792 [46\%] vs. 633/901 [70\%], $P=0.05 \%$ ), and frequent contact, i.e. working outside the house (13/79 [1.6\%] vs. $133 / 901$ [14\%], $P=0.05 \%)$. Of the 61 patients reporting COVID infection, 24 were shielding, similar to the non-COVID cohort (24/61 vs. 768/1632 $\left(\mathrm{Chi}^{2}=1.41, P=0.24\right)($ Table1).

\section{Discussion}

The impact of COVID-19 on patients with RD is poorly understood, while prevalence data and impacts of RD medication on COVID-19 rates are emerging the effects of public health policy in these group, such as stringent social isolation (shielding) is not understood. These data present a unique overview of both specific and wider effects of COVID-19 in a large cohort from a single-centre UK 
Table 4 Adherence to national public health advice on social distancing in patients advised to adhere to shielding (strict social distancing, $n=792$ ) and standard national advice $(n=901)$

\begin{tabular}{lccc}
\hline & $\begin{array}{l}\text { Total cohort } \\
n=1693\end{array}$ & $\begin{array}{l}\text { Shielding group } \\
n=792\end{array}$ & $\begin{array}{l}\text { Non-shielding group } \\
n=901\end{array}$ \\
\hline $\begin{array}{l}\text { Age, years (95\% CI) } \\
\text { Gender }\end{array}$ & $59.4(58.8,60.0)$ & $61.5(60.7,62.3)$ & $57.5(56.7,58.3)$ \\
Female & $1175(69.0 \%)$ & $555(70.1 \%)$ & $620(68.8 \%)$ \\
Male & $518(31.0 \%)$ & $237(29.9 \%)$ & $281(31.2 \%)$ \\
BAME & $104(6.1 \%)$ & $58(7.3 \%)$ & $46(5.1 \%)$ \\
Had COVID-19 & $61(3.6 \%)$ & $24(3 \%)$ & $37(4.1 \%)$ \\
Yes & $1632(96.4 \%)$ & $768(97 \%)$ & $864(95.9 \%)$ \\
No & $1372(81.0 \%)$ & $662(83.6 \%)$ & $710(78.8 \%)$ \\
In general, have you followed advice from the rheumatology department on shielding/distancing \\
Yes & $171(10.1 \%)$ & $62(7.8 \%)$ & $109(12.1 \%)$ \\
No & $150(8.9 \%)$ & $68(8.6 \%)$ & $82(9.1 \%)$ \\
Partially & $549(32.4 \%)$ & $414(52.3 \%)$ & $135(15.0 \%)$ \\
Over the past week, have you been shielding/distancing & $365(46.1 \%)$ & $633(70.3 \%)$ \\
Isolating (not left the house) & $998(58.9 \%)$ & $13(1.6 \%)$ & $133(14.8 \%)$ \\
Minimal contact with other & $146(8.6 \%)$ & & \\
Frequent contact with others & &
\end{tabular}

rheumatology cohort. Our approach gives more detail on RD patients than are available from the majority of current datasets.

Patients who had suffered COVID-19 were found to have significantly worse mental health score, while physical health scores were similar in COVID and non-COVID groups. In contrast, patients 'shielding' with RD had both lower physical and mental health scores (Table 2), while association does not prove causation these results, in keeping with other studies, suggests that shielding may have adverse effects on mental health [18], as well as negatively impacting patients RD symptom profile [19]. These differences were not seen in other proxy-markers of RD disease severity, such as biologic therapy (Table 2) and a large proportion of our questionnaire responses $(46.8 \%)$ were from 'high risk' patients. This requires further exploration.

Mortality from COVID-19 up to 1.5.20 for our cohort, $0.12 \%$, was similar to regional reported COVID-19 mortality, reported as $0.12 \%$ [10], in keeping with recent reports suggesting rheumatology patients taking immunomodulatory medications are at no increased risk of life-threatening complications associated with COVID-19 [8, 20]. These preliminary results show that $39 \%$ of COVID-19 patients in our survey were 'shielding', although some cases will have been caused by exposures before shielding introduction 22.03.20, this raises questions on the need for shielding need in RD patients.

There are several limitations to this study. At the time of the survey, no routine community COVID-19 testing was occurring, with testing reserved for secondary care [16]. However, patients may suffer few symptoms and not be diagnosed. We are aware of some patients with COVID-19 who were admitted to other hospitals outside our catchment area. Thus, our estimates of infection rates may be subject to error. We were not able to capture swab-negative COVID-19 patients (estimated to be 29\%) [21] not responding to our survey.

There were missing mobile numbers across all age groups, which has the potential to introduce bias. Patients without access to smartphone or internet technology are excluded; which is perhaps more likely in the elderly and more vulnerable groups in our population due to poorer healthcare and digital literacy, itself associated with social deprivation [22, 23]. The response rate, while consistent with other surveys is relatively low, particularly from the BAME population, and further exploration is required [5, 24].

Despite these limitations, these data contribute to this knowledge. While other studies assess either secondary or primary care datasets, that have limited cross-communication [11], all deaths in our study are captured via hospital EPR and linked primary care records, exemplified by a community case diagnosed post-mortem. The methodology used in this study is accepted among this population, illustrating the potential role of this methodology during a public health emergency.

\section{Conclusion}

Mortality within our rheumatology population, encompassing inflammatory and non-inflammatory disease patients, is not raised when compared to local overall COVID-19 mortality. Shielding patients were found to have significantly 
worse mental health scores compared to non-shielding patients. This association needs further exploration and an evaluation of the impacts of shielding on infection rates, mortality rates, and analysis of HRQoL scores over the pandemic is required. These data could be used internationally in shaping public health policy and rheumatology services moving forward. Our approach to patient-reported symptoms and behaviour has high acceptability among our population. The rapid response, and ease of communication, adds weight to use of SMS technology to support other National approaches including contact tracing could be adopted in future when distributing important information to patients quickly [25].

Acknowledgements The authors would like to thank the local patient participation groups and The Hibbs Lupus Trust for their input into the study and piloting the SMS technology. The views expressed are those of the authors and do not necessarily represent the views of the Royal Wolverhampton NHS Trust or NHS England. A part of this dataset was included in correspondence (in press) in response to Gianfransesco et al. Annals of the Rheumatic Diseases; Epub ahead of print. Doi: 10.1136/annrheumdis-2020-217871.

Author contributions The methodology was developed by JB, TPS and NC. The study was conceived by JB and NC and designed by JB, NC and TPS: it was internally reviewed and piloted by SR, NB, SV, TA, $\mathrm{HS}$, and BMS. The manuscript was drafted by $\mathrm{NC}$ and JB and reviewed by all the authors prior to final submission.

Funding The authors have not declared a specific grant for this research from any funding agency in the public, commercial or not-for-profit sectors.

Data availability Requests for access to data should be made to the corresponding author

Code availability Quality of Life scores were determined using the validated short form 12 scoring system. Data were analysed using SPSS version-26.

\section{Compliance with ethical standards}

Conflict of interest The authors declare no competing interests.

Ethical approval This work was given rapid approval in lieu of the COVID-19 pandemic by the Royal Wolverhampton NHS Trust Management Committee (25.4.2020) as a service evaluation. As per NHS England ethics requirements, it is exempt from formal NHS Research Ethics Committee review. This work is compliant with European Union General Data Protection Regulation; no additional consent for sending healthcare SMS messages is required." (Reference) This ethical statement is included on the submitted title page and embedded in the "Methods" section of the main text.

Patient and public involvement Patients and a national charity (the Hibbs Lupus Trust) were involved in the design, content, piloting and acceptability of our questionnaire and methodology, as described in the "Methods" section of the paper.

Patient consent Patients were approached at the point of data collection; patients received SMS message inviting them to participate by following the link and completing the survey-participation was completely voluntary. A briefing page prior to completing the survey (supplement 1) informed participants what the service evaluation entailed, following reading this patients were asked whether they gave consent to continue; if patients opted not to continue, no further contact was made.

\section{References}

1. EULAR. (2020) Policy statement on COVID-19. Available from: https://www.eular.org/eular_guidance_for_patients_covid 19_outbreak.cfm. Accessed 20 May 2020.

2. British Society for Rheumatology. (2020) COVID-19 (Coronavirus)-update for members. Available from: https://www. rheumatology.org.uk/news-policy/details/covid19-coronaviru s-update-members. Accessed 25 May 2020.

3. Price E, MacPhie E, Kay L, Lanyon P, Griffiths B, Holroyd C, Abhishek A, Youngstein T, Bailey K, Clinch J, Shaikh M, Rivett A (2020) Identifying rheumatic disease patients at high risk and requiring shielding during the COVID19 pandemic. Clin Med (London, England). https://doi.org/10.7861/clinmed.2020-0160 (Published Online First: May 2020)

4. Public Health England. (2020) Guidance on shielding and protecting people defined on medical grounds as extremely vulnerable from COVID-19. Available from: https://www.gov.uk/gover nment/publications/guidance-on-shielding-and-protecting-extre mely-vulnerable-persons-from-covid-19/guidance-on-shieldingand-protecting-extremely-vulnerable-persons-from-covid-19. Accessed 25 May 2020.

5. Bateman J, Mulherin D, Hirsch G, Venkatachalam S, Sheeran T (2020) Rapid distribution of information by SMS-embedded video link to patients during a pandemic. Lancet Rheumatol. https://doi. org/10.1016/S2665-9913(20)30126-0

6. Haberman R, Axelrad J, Chen A, Castillo R, Yan D, Izmirly P, Neimann A, Adhikari S, Hudesman D, Scher JU (2020) Covid19 in immune-mediated inflammatory diseases - case series from New York. N Engl J Med. https://doi.org/10.1056/NEJMc20095 67

7. Thorlund K, Dron L, Park J, Hsu G, Forrest JI, Mills EJ (2020) A real-time dashboard of clinical trials for COVID-19. Lancet Digit Health. https://doi.org/10.1016/S2589-7500(20)30086-8

8. Gianfrancesco M, Hyrich KL, Al-Adely S, Carmona L, Danila MI, Gossec L et al (2020) Characteristics associated with hospitalisation for COVID-19 in people with rheumatic disease: data from the COVID-19 global rheumatology alliance physician-reported registry. Ann Rheum Dis 79:859

9. Public Health England. (2020) Weekly Coronavirus Disease 2019 (COVID-19) Surveillance Report. Summary of COVID-19 surveillance systems. assets.publishing.service.gov.uk. Available from: https://assets.publishing.service.gov.uk/government/uploa ds/system/uploads/attachment_data/file/888254/COVID19_Epide miological_Summary_w22_Final.pdf. Accessed 20 May 2020

10. NHS England. (2020) COVID-19-daily-announced-deaths-24April-2020. Available from: https://www.england.nhs.uk/stati stics/statistical-work-areas/covid-19-daily-deaths/. Accessed 20 May 2020

11. Williamson E, Walker A, Bhaskaran K, Bacon S, Bates C, The OpenSAFELY Collaborative (2020) OpenSAFELY: factors associated with COVID-19-related hospital death in the linked electronic health records of 17 million adult NHS patients. MedRxiv. https://doi.org/10.1101/2020.05.06.20092999

12. Mehra MR, Desai SS, Ruschitzka F, Patel AN (2020) RETRACTED: Hydroxychloroquine or chloroquine with or 
without a macrolide for treatment of COVID-19: a multinational registry analysis. Lancet S0140-6736(20):31324-31326

13. Hurst N, Ruta D, Kind P (1998) Comparison of the MOS Short Form-12 (SF12) Health status questionnaire with the SF36 in patients with rheumatoid arthritis. Br J Rheumatol 1(37):862-869

14. Martinengo L, Spinazze P, Car J (2020) Mobile messaging with patients. BMJ 368:m884

15. Gupta K, Venkatachalam S, Sheeran T, Bateman J (2016) How do we plan outpatient rheumatology services? an electronic casemix service evaluation of more than 1000 consecutive new and follow-up clinics slots. Rheumatology 55:i130-i131. https://doi. org/10.1093/rheumatology/kew133.022

16. National Institute of Clinical Excellence (NICE). (2020) Coronavirus (COVID-19): getting tested. Available from: https://www. gov.uk/guidance/coronavirus-covid-19-getting-tested. Accessed 26 May 2020.

17. Docherty AB, Harrison EM, Green CA, Hardwick H, Pius R, Norman $L$ et al (2020) Features of 16,749 hospitalised UK patients with COVID-19 using the ISARIC WHO clinical characterisation protocol. BMJ. https://doi.org/10.1101/2020.04.23.20076042

18. Someshwar H, Sarvaiya P, Desai S, Gogri P, Someshwar J, Mehendale P, Bhatt G (2020) Does social distancing during the lock down due to Covid-19 outbreak in mumbai affect quality of life? Int J Clin Biomed Res 6(2):1-4. https://doi.org/10.31878/ ijcbr.2020.62.01

19. Vallerand IA, Patten SB, Barnabe C (2019) Depression and the risk of rheumatoid arthritis. Curr Opin Rheumatol 31(3):279-284

20. Monti S, Balduzzi S, Delvino P, Bellis E, Quadrelli VS, Montecucco C (2020) Clinical course of COVID-19 in a series of patients with chronic arthritis treated with immunosuppressive targeted therapies. Ann Rheum Dis 79:667. https://doi.org/10.1136/ annrheumdis-2020-217424

21. Arevalo-Rodriguez I, Buitrago-Garcia D, Simancas-Racines D, Zambrano-Achig P, del Campo R, Ciapponi A et al (2020) Falsenegative results of initial rt-pcr assays for covid-19: a systematic review. PLoS ONE 15:e0242958

22. Helsper E. (2008) Digital inclusion: an analysis of social disadvantage and the information society. Available from: http://eprin ts.lse.ac.uk/id/eprint/26938.

23. McEntegart A, Morrison E, Capell HA et al (1997) Effect of social deprivation on disease severity and outcome in patients with rheumatoid arthritis. Ann Rheum Dis 56:410-413. https:// doi.org/10.1136/ard.56.7.410

24. Bexelius C, Merk H, Sandin S, Ekman A, Nyrén O, KühlmannBerenzon S et al (2009) SMS versus telephone interviews for epidemiological data collection: feasibility study estimating influenza vaccination coverage in the Swedish population. Eur J Epidemiol 24(2):73-81

25. NHSX. NHS COVID-19 App. 2020. Available from: https://www. nhsx.nhs.uk/covid-19-response/nhs-covid-19-app/. Accessed 20 May 2020

Publisher's Note Springer Nature remains neutral with regard to jurisdictional claims in published maps and institutional affiliations. 